\title{
A POPULATION BASED SURVEY ON HIV PREVALENCE IN NAGALAND, INDIA
}

\author{
Bachani $\mathrm{D},{ }^{1}$ Sogarwal $R,{ }^{2}$ Rao $\mathrm{KS}^{3}$ \\ 'Deputy Director General, ${ }^{2}$ Program Officer, ${ }^{3}$ Director General \\ National AIDS Control Organization, Ministry of Health and Family Welfare \\ Government of India, New Delhi, INDIA
}

\begin{abstract}
The primary aim of the present study was to determine the prevalence of HIV infection in Nagaland and to study knowledge and attitude of study participants towards HIVIAIDS and related Government programs. A population based survey was carried out during April-October, 2007. Stratified sampling technique was adopted with an anonymous, linked design for HIV testing using Dried Blood Spot Testing Method (Tri-Dot). A total of 1965 households were interviewed in which 5661 eligible respondents (male:15-54 years and female:15-49 years) completed the interview. The total individual response rate was 95.2\%. Blood samples were collected from 5637 respondents. Results revealed that the prevalence of HIV was estimated to be $0.74 \%$ in Nagaland. Dimapur was identified as the only district where HIV prevalence was higher than $1 \%$. Wokha $(0.98 \%)$ and Tuensang $(0.92 \%)$ also had higher prevalence compared to other districts. Knowledge of HIVIAIDS prevention methods and the services available under National HIVIAIDS program was low. Further steps therefore need to be taken to ensure higher utilization of services.
\end{abstract}

Keywords : Population based survey, HIV prevalence, Nagaland

\section{INTRODUCTION}

Human Immunodeficiency Virus (HIV) infection and Acquired Immune Deficiency Syndrome (AIDS) is posing a threat to the survival of human beings. The prevalence and magnitude of HIVIAIDS is high in countries like South Africa and Nigeria where the epidemic has affected the general population. ${ }^{1}$ To estimate the burden of HIVIAIDS, valid data on the prevalence of HIV are required. Population based data

\section{Correspondence to}

Dr. Ruchi Sogarwal

Evaluation \& Operational Research Division

National AIDS Control Organization

$6^{\text {th }}$ Floor Chanderlok Building

36, Janpath, New Delhi-110001, INDIA

E-mail : ruchi.dr@gmail.com are especially valuable as they provide generalizable unbiased estimates of health and disease outcomes in the community as a whole. ${ }^{2}$ Often, in the absence of population based data, estimates are based on data from sentinel surveillance including antenatal clinics. Antenatal prevalence of HIV is easier to measure, can be repeated and is taken as proxy indicator of general population. However, it is evident from several studies that the estimates of disease prevalence from sentinel surveillance may differ significantly from population based data. ${ }^{3,4,5,6,7}$

Sentinel surveillance is being undertaken in India annually since 1998 to assess trends of HIV infection, estimate the HIV prevalence and disease burden. Though sentinel sites have been gradually increased over the years, ${ }^{8,9}$ limited geographical coverage especially in remote, rural and hilly areas and the 
absence of data for men has raised questions on use of such data for estimating prevalence of HIV. To obtain a representative HIV estimate for Nagaland, a need was felt to conduct a population study. HIV testing under National Family Health Survey (NFHS-3) was limited to five out of six high HIV prevalence states (except Nagaland) and only one low-prevalent State (Uttar Pradesh). ${ }^{10}$ In response to this, the NFHS Round-3 incorporated HIV testing and related issues in the survey. This led to valid and representative data on HIV prevalence and comprehensive information on knowledge and attitudes towards HIVIAIDS, high-risk sexual behavior and practices related to HIV testing in India.

The present study was undertaken to obtain a population based estimate of HIV prevalence in Nagaland, the only high prevalence state not covered under NFHS-3. Comparing the results of this survey with the sentinel surveillance data will throw some light on the true situation of Nagaland and modify future programmes. Besides, studying the level of knowledge and attitude of a population towards HIVIAIDS and services under National AIDS Control Program PhaseIII (NACP-III) the study will reveal the extent to which services have reached the community.

\section{STUDY DESIGN AND SAMPLING METHOD}

The present study is a descriptive cross-sectional population based study conducted in the State of Nagaland in India. A representative sample of the general population of Nagaland aged 15-49 women and 15-54 men was selected using the stratified sampling design. Population data was collected from Census, 2001.11 In the rural areas, samples were selected in two stages; the selection of Primary Sampling Units (PSUs), which were villages, with probability proportional to population size (PPS) at the first stage, followed by the random selection of households within each PSU in the second stage. In urban areas, a three-stage procedure was followed. In the first stage, census wards were selected with PPS sampling. In the next stage, one Census Enumeration Block (CEB) was systematically selected from each sample. In the final stage, households were randomly selected within each sample CEB.

\section{a) Sample Selection in Rural Areas}

For rural areas, based on the 2001 Census, list of villages served as the sampling frame. The list was stratified by a number of variables. The first level of stratification was based on HIV prevalence (using HIV Sentinel Surveillance, 2007) ${ }^{9}$ with districts being subdivided into subgroups. Within each of these subgroups, villages were further stratified using following selected variables (a) total percent of male in marginal activities and non-workers (b) female literacy rate.

From this sampling frame, villages were selected systematically with probability proportional to the 2001 Census population of the village. Small villages with population of 300 or less were linked with an adjoining village to form PSUs with a population of 300 to 600 . Villages with less than 50 persons were excluded from the sampling frame. Further, of each selected census enumeration blocks or villages, mapping, house-listing and enumeration of eligible population were carried out. The listing provided a necessary frame for selecting the households. The household listing operation facilitated in preparing an updated layout sketch maps of each selected PSU, assigning numbers to structures, recording addresses of these structures, identifying residential structures, and giving an identification number to each household and record other information of each household. If there were large sample villages (with more than 600 persons), they were segmented into two or more segments and one of the segment was selected randomly. In such case, household listing was carried out only in the selected segments.

The households to be interviewed were selected with equal probability from the household list in each area using systematic sampling. This method provides equal probability of selection of each household and eligible person within the household. Each survey team supervisor provided updated household listing, layout sketch map, and the list of selected households for each stratum. All the selected households were contacted during the main survey. Three attempts were made before the household was dropped. No replacement was made if a selected household was locked during the data collection. 


\section{b) Sample Selection in Urban Areas}

The procedure adopted for the first stage of the sample design in urban areas was similar to the one followed in rural areas. The 2001 Census list of wards was arranged according to districts by HIV prevalence and followed by the total percent of male marginal workers and non-workers and female literacy as in rural areas. A sample of wards was selected systematically with probability proportional to size. Next, one census enumeration block, consisting of approximately 300 600 populations, was selected from each selected ward using the PPS method.

Sample size was calculated using the HIV prevalence of Nagaland at the sentinel surveillance of year 2006, with 95 percent confidence interval $(\mathrm{Cl})$ and coverage of 85 percent eligible population to this method. The sample size was 6000 eligible persons consisting of men in age group of 15-54 years and women in 15-49 years.

\section{TRAINING, DATA COLLECTION AND DATA PROCESSING}

i) Training : Centralized training was held to train field staff at Dimapur, Nagaland The purpose of this training was to ensure uniformity in data collection procedures in different districts. Training involved classroom sessions (including, the content of questionnaires, lectures on HIVIAIDS and family planning methods) and field practice in rural and urban areas. It also involved mapping and household listing operations. Experts from International Institute for Population Sciences (IIPS) and Consultants from National AIDS Control Organization (NACO) carried out the 5 day training.

Microbiologist from District hospital, Kohima and labtechnicians from Integrated Counseling and Testing Center (ICTCS) and Antiretroviral Treatment (ART) centers were involved in the survey to collect the blood samples and HIV testing. Training and Supervision of these staff were done by Regional Medical Research Center, Dibrugargh (ICMR). They were trained in methods of blood collection, ethical requirements, and biohazard waste disposal. Biomarker specialists from ICMR and NACO served as resource persons. Data entry operators were trained in office editing of questionnaires, data cleaning and data entry. A separate training course of three days duration was conducted at NACO.

ii) Data Collection : Data collection was carried out in two Rounds (June-October 2007); Round I-Mapping and House listing and Round II- Household and Individual Interview.

The fieldwork was carried out by eight interviewing teams, each team consisting of one field supervisor and two interviewers. Male and female interviewers were assigned respondents of the same sex to ensure that respondents felt comfortable talking about topics that they may find somewhat sensitive. Research Coordinators were hired with the responsibility for the overall management of the field team. Supervisors were also responsible to examine questionnaires for completeness, consistency, and legibility of the information collected, and to ensure that all necessary corrections and clarifications were made while still in the field. Special attention was paid to missing information, skip instructions, filter questions and age information. If major inconsistencies were detected, the interviewers were required to revisit the respondent to rectify the inconsistencies.

In addition, research coordinators and the field supervisor conducted spot checks to verify the accuracy of key information, particularly with respect to the eligibility of respondents. NACO and Nagaland State AIDS Control Society (NSACS) officials also visited the field sites to monitor data collection operations.

iii) Data Processing : All completed questionnaires were sent to NACO through Nagaland State Control Society for editing and data processing (including office editing, coding, data entry, and machine editing). Although in field every completed questionnaire was examined, the questionnaires were re-edited at NACO by specially trained office editors.

Dried Blood Spot Testing Method (Tri-Dot) was used to collect blood samples on filter paper in the field and tested in the laboratory at Naga Hospital, Kohima. 
An anonymous, linked design for HIV testing was adopted in the survey. Quality control was performed at the Regional Medical Research Center, Dibrugargh (ICMR).

Informed consent was obtained from each respondent included in the study in which participants were fully informed of the procedure and potential risks. The participation of each respondent was fully voluntary. In the case of respondent age 15-17 years, consent was taken from a parent or guardian present in the household at the time of the survey.

Data on HIV sero-positivity amongst clients of Integrated Counseling and Testing Center (ICTC) were extracted from Computerized Management Information System (CMIS) at National AIDS Control Organization to analyzed its districts-wise trends for the period 2003-2007².

Technical and ethical approval was obtained from the Technical Resource Group on Research and
Development constituted by the Ministry of Health and Family Welfare, Government of India.

\section{STATISTICAL ANALYSIS}

Statistical Analysis was done using Epi-Info (ver. 3.5.1, 2008) and SPSS 15.0 (SPSS, Inc., Chicago, IL.USA). Univariate and bivariate analysis of sociodemographic and other variables were performed. The Pearson's chi-square test, the adjusted Mantel Haenszel's test were used to analyze the differences in the categorical data. A p-value $<0.05$ was considered significant.

\section{RESULTS AND DISCUSSION}

A total of 1965 households were interviewed in which 5945 were the eligible respondent (male:15-54 years and female:15-49 years). Complete information was obtained from 5661 persons with a response rate of 95.2\% and blood samples were collected from 5637 $(94.8 \%)$ of eligible respondents (Table 1 ).

Table 1: Information of Households $(\mathrm{HH})$ and Respondents surveyed in Nagaland, India

\begin{tabular}{|c|c|}
\hline & Number \\
\hline HH selected & 2132 \\
\hline HH occupied & 2014 \\
\hline HH interviewed & 1965 (RR-97.6) \\
\hline $\mathrm{HH}$ refused/vacant/eligible respondent not found & 19 \\
\hline HH Population & 10467 \\
\hline Eligible respondent & 5945 \\
\hline Eligible respondent interview completed & 5661 (RR-95.2\%) \\
\hline Eligible respondent not at home/refused/postponed/partly completed/other & 284 \\
\hline Eligible Male respondent (15-54 years) & 3064 \\
\hline - $\quad$ Male interviews completed & 2900 (RR-94.6\%) \\
\hline Eligible Female respondent (15-49 years) & 2881 \\
\hline - $\quad$ Female interviews completed & 2761 (RR-95.8\%) \\
\hline Blood Samples Collected & 5637 (RR-99.5\%) \\
\hline - Blood Samples Collected-male & 2887 \\
\hline - Blood Samples Collected-female & 2750 \\
\hline
\end{tabular}

${ }^{*}$ RR: Response Rate 
The distribution of male and female respondents was similar and declining with age $(P>0.05)$. More than $3 / 4^{\text {th }}$ of the population belonged to rural areas. The distribution of the study population by completed number of years of education reveals that comparatively more women (14.6\%) were illiterate as compared to men (6.6\%). Among those who had higher education nearly 21 percent of the women have had 10 or more years of education, compared with 33 percent of men $(p<0.01)$.
In the study population, about 46 percent of the respondents were married and living with spouse at the time of the survey. Respondents who never married accounted for $49 \%$ of female respondents and $53 \%$ of male respondents. Majority (95\%) of the male and female respondent were Christian by religion. Overall, 45 percent of study population was employed at the time of survey. Nearly $1 / 4^{\text {th }}$ of the respondents were agricultural workers or unskilled workers. Twenty four (24\%) of the respondents reported that they were away from home during the last 12 months (Table 2).

Table 2: Percentage distribution of respondent by background characteristics in Nagaland, India

\begin{tabular}{|c|c|c|c|c|}
\hline Background Characteristics & $\begin{array}{c}\text { Male } \\
(\mathrm{N}=2900)\end{array}$ & $\begin{array}{l}\text { Female } \\
(\mathrm{N}=2761)\end{array}$ & Total $(\mathrm{N}=5661)$ & \\
\hline \multicolumn{5}{|l|}{ Age (in completed years) } \\
\hline $15-19$ & $861(29.7)$ & 918(33.2) & $1779(31.4)$ & \multirow{5}{*}{$\begin{array}{l}\text { Chi-square }=0.57 \\
d f=3 ; p=0.90 \mathrm{NS}\end{array}$} \\
\hline $20-29$ & $790(27.2)$ & $836(30.3)$ & $1626(28.7)$ & \\
\hline 30-39 & $501(17.3)$ & $523(18.9)$ & 1024(18.1) & \\
\hline $40-49$ & $477(16.4)$ & $484(17.5)$ & $961(17.0)$ & \\
\hline $50-54$ & $271(9.3)$ & - & $271(4.8)$ & \\
\hline \multicolumn{4}{|l|}{ Residence } & \multirow{3}{*}{$\begin{array}{l}\text { MH Chi-square }=0.036 \\
d f=1 ; p=0.036 \mathrm{~S}\end{array}$} \\
\hline Rural & 2239(77.2) & 2195(79.5) & $4434(78.3)$ & \\
\hline Urban & $661(22.8)$ & $566(20.5)$ & $1227(21.4)$ & \\
\hline \multicolumn{4}{|l|}{ Education } & \multirow{5}{*}{$\begin{array}{l}\text { Chi-square }=179.05 ; \mathrm{df}=3 \text {; } \\
\mathrm{p}=0.001 \mathrm{HS}\end{array}$} \\
\hline Illiterate & $192(6.6)$ & 404(14.6) & $596(10.5)$ & \\
\hline Primary (1-5 years) & $413(14.2)$ & $513(18.6)$ & $926(16.4)$ & \\
\hline Secondary (6-10 years) & 1351(46.6) & $1277(46.3)$ & $2628(46.4)$ & \\
\hline Higher (above 10 years) & $944(32.6)$ & $567(20.5)$ & $1511(26.7)$ & \\
\hline \multicolumn{4}{|l|}{ Marital status } & \multirow{5}{*}{$\begin{array}{l}\text { Chi-square=44.86; df=3; } \\
p=0.001 \text { HS }\end{array}$} \\
\hline Married living with spouse & $1292(44.5)$ & $1327(48.1)$ & $2618(46.2)$ & \\
\hline Married living alone & $52(1.8)$ & $17(0.6)$ & $69(1.2)$ & \\
\hline Divorced/Separated/Widower & $31(1.1)$ & $75(2.7)$ & $107(1.9)$ & \\
\hline Never married & $1525(52.6)$ & 1342(48.6) & $2867(50.7)$ & \\
\hline \multicolumn{4}{|l|}{ Religion } & \multirow{3}{*}{$\begin{array}{l}\text { MH Chi-square=18.44; } \\
d f=1 ; p=0.001 \text { HS }\end{array}$} \\
\hline Christian & $2709(93.4)$ & $2650(96.0)$ & $5359(94.7)$ & \\
\hline Non-Christian & 191(6.6) & $111(4.0)$ & $302(5.3)$ & \\
\hline \multicolumn{4}{|l|}{ Occupation } & \multirow{8}{*}{$\begin{array}{l}\text { Chi-square=784.1; df=6; } \\
p=0.001 \text { HS }\end{array}$} \\
\hline Agriculture/Unskilled worker & $765(26.4)$ & $530(19.2)$ & $1295(22.9)$ & \\
\hline Truck/Auto/Taxi Driver/Cleaner & $87(3.0)$ & $22(0.8)$ & $109(1.9)$ & \\
\hline Service & $562(19.4)$ & $215(7.8)$ & $777(13.7)$ & \\
\hline Business & 203(7.0) & $102(3.7)$ & $305(5.4)$ & \\
\hline Unemployed/ Housewife & $241(8.3)$ & $942(34.1)$ & $1183(20.9)$ & \\
\hline Student & $911(31.4)$ & $939(34.0)$ & $1850(32.7)$ & \\
\hline Other & $131(4.5)$ & $11(0.4)$ & $142(2.5)$ & \\
\hline
\end{tabular}




\begin{tabular}{|c|c|c|c|c|}
\hline Last 12 months away from home & $838(28.9)$ & 514(18.6) & 1352(23.9) & $\begin{array}{l}\text { MH Chi-square=82.21; } \\
d f=1 ; p=0.001 \text { HS }\end{array}$ \\
\hline \multicolumn{4}{|c|}{ How often away from home in last 12 months ( $N=1352)$} & \\
\hline More than once a week & 183(21.8) & $65(12.6)$ & 248(18.3) & \\
\hline Once or twice a month & $365(43.7)$ & 166(32.2) & $531(39.3)$ & \\
\hline Once every 2 or 3 months & $74(8.8)$ & $44(8.7)$ & $118(8.7)$ & \\
\hline Once every 4 to 6 months & $75(8.9)$ & $28(5.4)$ & 103(7.6) & \\
\hline Once or twice a year & $141(16.8)$ & $211(41.1)$ & $352(26.0)$ & \\
\hline
\end{tabular}

\section{KNOWLEDGE TOWARDS HIV/AIDS}

All women and men interviewed were asked if they had ever heard of a disease called AIDS. Respondents who had heard of AIDS were then asked a series of questions to ascertain the extent of their knowledge. Analysis indicates that 92 percent of the respondents (95\% males and $89 \%$ females) had ever heard of HIVIAIDS in Nagaland $(p<0.001)$. These estimates are higher than NFHS-3 particularly in females. ${ }^{10}$ Though National Behavioral Sentinel Surveillance ${ }^{13}$ does not provide information separately for Nagaland, it presents the combined percentages of northeastern states excluding Manipur. Results of this study are consistent with those of Manipur (92.1\%) and Northeastern states (93.4\%). It has been found that friends/relatives (54.9\%) and posters / hoardings/ newspapers (48.9\%) were the major source of information for the knowledge about HIVIAIDS (Table 3).
HIVIAIDS prevention programmes focus their efforts and messages on promoting three prevention behaviors: delaying sexual debut among young persons (abstinence), limiting the number of sex partners/staying faithful to one partner (being faithful), and use of condoms. The population based survey has also made an attempt to assess the proportion of women and men who were aware of these HIVIAIDS prevention methods (Fig.1). About $53 \%$ of respondents were aware that a condom should be used correctly every time during sex. Almost same percentage of respondents were aware of other prevention methods i.e. having one uninfected sex partner who has no other partner (58\%) and abstinence from sex (57\%). It is notable that knowledge about methods of HIV prevention was not found to be significant between men and women in Nagaland ( $p>0.05)$.

\begin{tabular}{|c|c|c|c|}
\hline & Male $\mathrm{N}=2900$ ) & Female (2761) & Total (5661) \\
\hline $\begin{array}{l}\text { Percentage of respondent who have heard of HIVI } \\
\text { AIDS }\end{array}$ & $\begin{array}{l}2758 \\
(95.1)\end{array}$ & $2463(89.2)$ & $5221(92.2)$ \\
\hline \multicolumn{4}{|l|}{ MH Chi-square=68.59; df=1; $p<0.001$ HS } \\
\hline \multicolumn{4}{|l|}{ Source of Information } \\
\hline Radio & 45.9 & 46.0 & 45.9 \\
\hline Television & 36.1 & 33.1 & 34.7 \\
\hline Cinema & 3.8 & 1.9 & 2.9 \\
\hline Health Workers & 38.1 & 30.2 & 34.4 \\
\hline Spouse/Partner & 2.7 & 5.0 & 3.8 \\
\hline Friends/Relatives & 43.1 & 68.2 & 54.9 \\
\hline Posters/Hoardings/Newspaper & 58.5 & 38.2 & 48.9 \\
\hline School Teacher & 16.6 & 14.1 & 15.4 \\
\hline Other & 18.5 & 8.8 & 13.9 \\
\hline
\end{tabular}




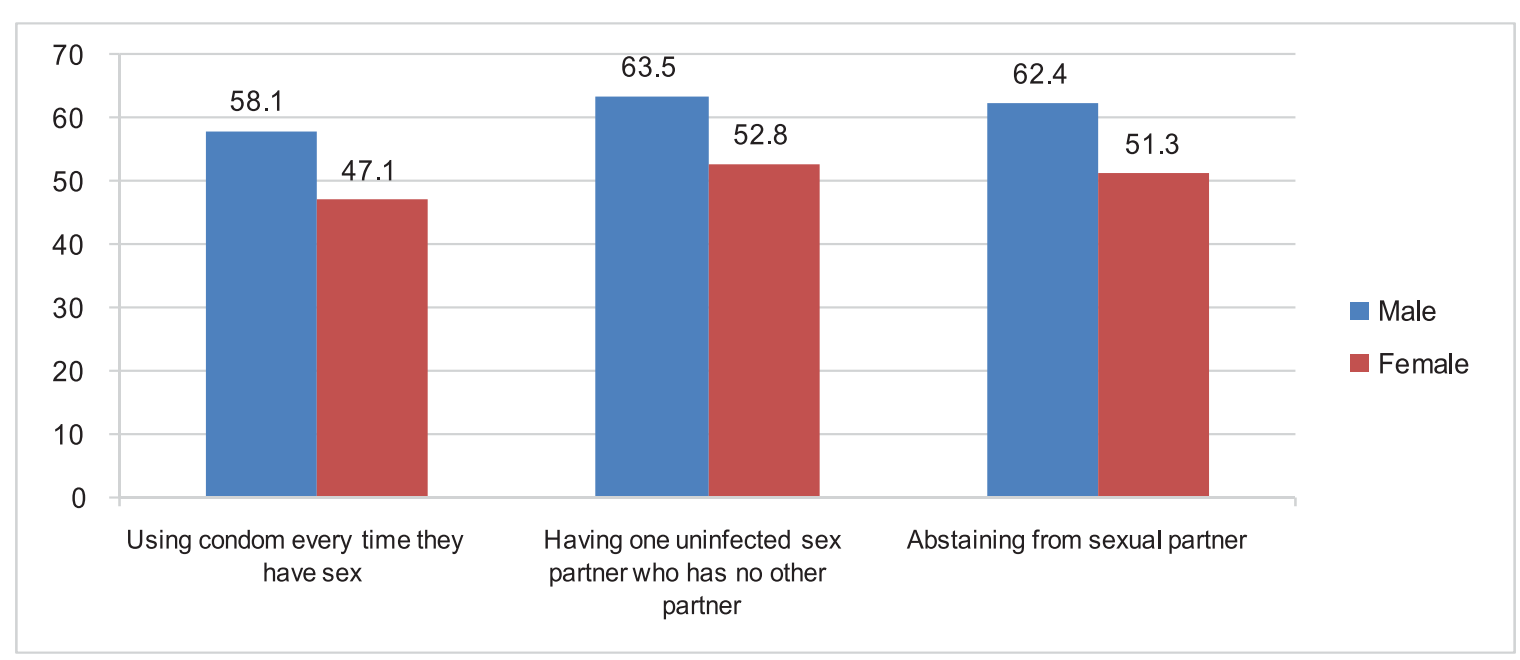

Figure 1: Proportion of respondent aware of HIV Prevention Methods in Nagaland, India

This study revealed that the larger proportions $(88 \%)$ of respondents were aware that a person can get infected by getting injections with a shared needle and from the infected mother to newborn child. Knowledge regarding the transmission of virus through breastfeeding was low. In Nagaland many persons also erroneously believed that HIVIAIDS can be transmitted by mosquito bites $(59.5 \%)$ and that a person can get infected by sharing food with someone who is HIV positive (72.8\%). Only $54 \%$ of the respondents had understanding that a healthy looking person could be infected with HIV (Fig.2).

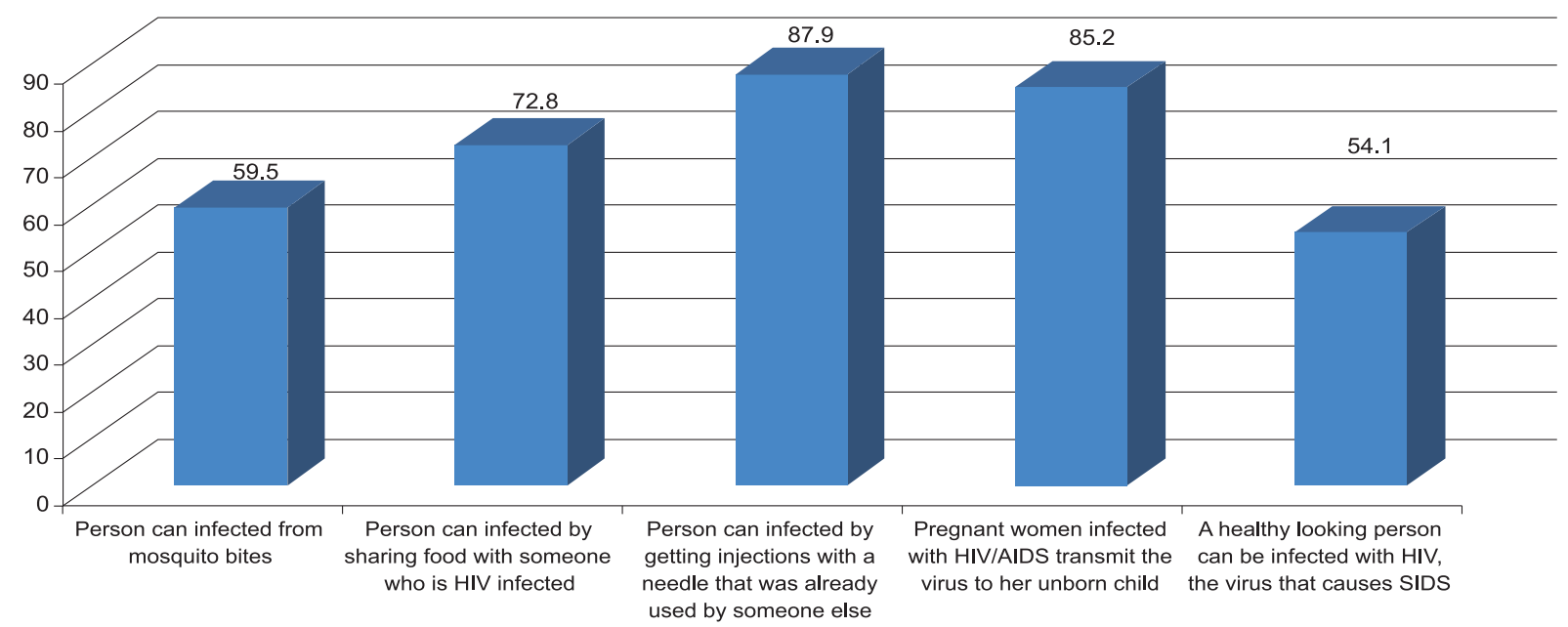

Figure 2: Proportion of respondent who are aware about HIV/AIDS and its transmission in Nagaland, India

\section{KNOWLEDGE OF SERVICES UNDER NACP-III AND HIV TESTING}

Larger proportion (64\%) of the respondents was aware about voluntary counseling and HIV testing services whereas less than one third (29\%) respondents were aware of STI control program. Only $45 \%$ were aware of the ART program (Figure 3). 


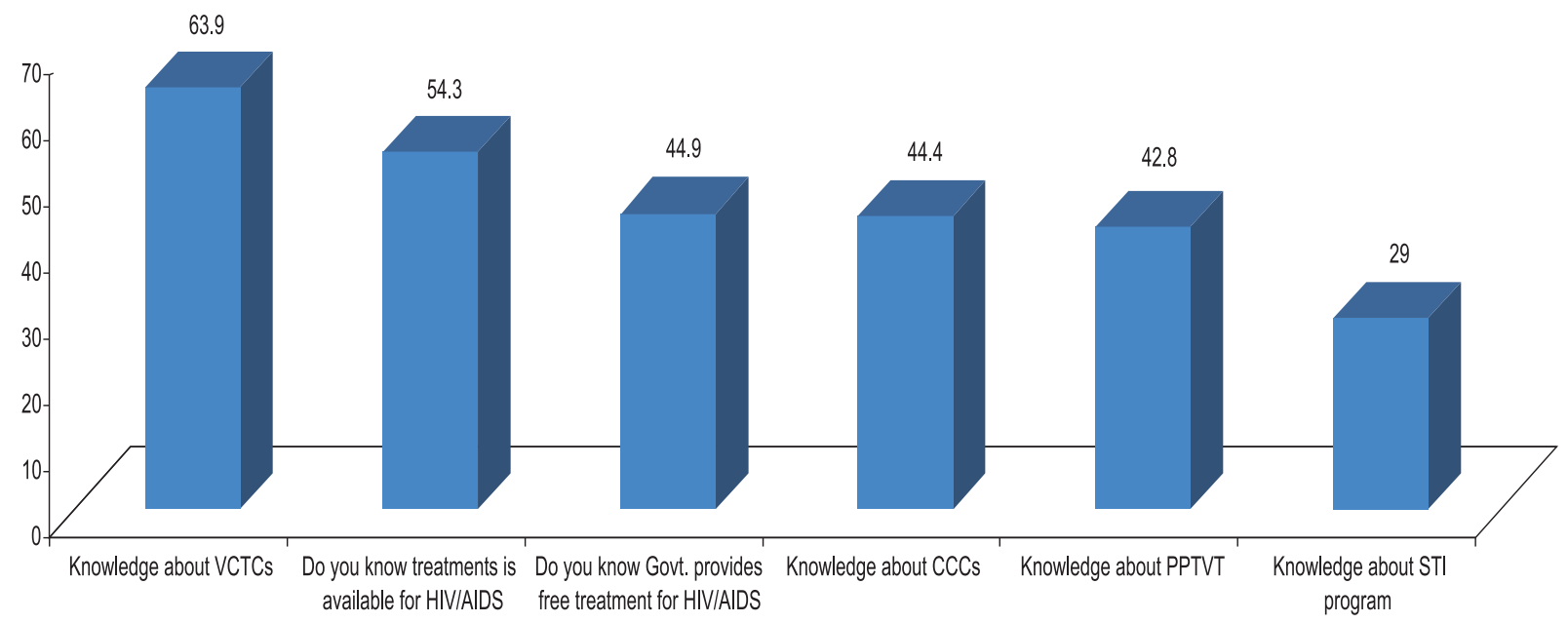

Figure 3: Proportion of respondent who are aware of HIV/AIDS program implemented by Government in Nagaland, India

One of the major challenges of the HIV prevention program in India is the ignorance and denial of HIV risk. To obtain information on HIV testing, all respondents were asked whether they had ever been tested for HIVIAIDS. Study indicates that only $10 \%$ of respondents had ever been tested for HIV. Amongst those tested for HIV during the preceding 12 months, $72 \%$ sought services at ICTCs. It was observed that post-test counseling services were sought by only $27 \%$ of those tested in preceding 12 months (Table 5).

Table 4: Percentage of respondent who had ever been tested for HIV in Nagaland, India

\begin{tabular}{|c|c|c|c|c|c|}
\hline & $\begin{array}{l}\text { Male } \\
\text { N=2758 } \\
\text { No (\%) }\end{array}$ & $\begin{array}{l}\text { Female } \\
\mathrm{N}=2463 \\
\mathrm{No}(\%)\end{array}$ & $\begin{array}{l}\text { Total } \\
\text { N=5221 } \\
\text { No (\%) }\end{array}$ & $\begin{array}{l}\text { Chi- } \\
\text { square }\end{array}$ & $P$ value \\
\hline Percentage who had been ever tested for HIV & $268(9.7)$ & 266(10.8) & $534(10.2)$ & 1.66 & $p>0.05$ NS \\
\hline $\begin{array}{l}\text { Percentage who had undergone voluntary HIV } \\
\text { testing }\end{array}$ & 209(77.2) & 188(70.6) & $396(73.9)$ & 3.73 & $P<0.05 \mathrm{~S}$ \\
\hline Percentage who were given the result of HIV test & $161(59.9)$ & 183(68.8) & $344(64.4)$ & 4.42 & $P<0.05 \mathrm{~S}$ \\
\hline $\begin{array}{l}\text { Percentage who had undertaken HIV testing in last } \\
12 \text { months }\end{array}$ & $86(32.2)$ & 132(49.4) & 218(40.9) & 16.26 & $P<0.001 \mathrm{HS}$ \\
\hline Percentage who received pre-test counseling & $46(53.9)$ & $77(59.1)$ & $123(56.5)$ & 0.49 & $P>0.05 \mathrm{NS}$ \\
\hline $\begin{array}{l}\text { Percentage who received post-test counseling } \\
\text { Place where most recent HIV test done }\end{array}$ & $13(14.6)$ & $52(39.4)$ & $64(27.1)$ & 14.6 & $P<0.001 \mathrm{HS}$ \\
\hline - Government hospital/ICTC & $48(55.8)$ & $116(88.8)$ & $164(75.2)$ & \multirow{3}{*}{39.62} & \multirow{3}{*}{$P<0.001 \mathrm{HS}$} \\
\hline - Private clinic/Hospital & $9(10.5)$ & $12(8.9)$ & $21(9.6)$ & & \\
\hline - Other & $29(33.7)$ & $4(2.3)$ & 33 (15.1) & & \\
\hline
\end{tabular}

\begin{tabular}{|c|c|c|c|c|}
\hline Area & PSUs surveyed & $\begin{array}{l}\text { Blood samples } \\
\text { tested }\end{array}$ & HIV+ samples & HIV+\% \\
\hline Rural & 24 & 4497 & 30 & 0.67 \\
\hline Urban & 6 & 1140 & 12 & 1.05 \\
\hline
\end{tabular}




\begin{tabular}{|lccc|}
\hline Table 5: Percentage of respondents found HIV positive in Nagaland, India & \\
District & $\begin{array}{c}\text { Blood samples } \\
\text { tested }\end{array}$ & Number positive for HIV & $\begin{array}{c}\% \\
\text { positives }\end{array}$ \\
Dimapur & 942 & 11 & 1.2 \\
Mon & 211 & 0 & 0 \\
\hline Phek & 618 & 5 & 0.8 \\
Tuensang & 1192 & 11 & 0.9 \\
Wokha & 715 & 8 & 1.0 \\
Zunheboto & 991 & 5 & 0.5 \\
Kohima & 968 & 2 & 0.2 \\
Total & 5637 & 42 & 0.7 \\
\hline
\end{tabular}

Based on the above results, there is a need of awareness programs to enhance knowledge of HIVI AIDS prevention methods and utilization of services made available by the State. Steps need to be taken to strengthen counseling services through refresher training of counselors and community based awareness program.

\section{HIV Prevalence}

Out of total eligible respondent interviewed (5945) in the survey, blood samples were collected from 5637 eligible (94.8\%) respondent.

The prevalence of HIV was estimated to be $0.74 \%$ in Nagaland which is higher than national average of $0.36 \%$. Though by WHO definition, it is not a high prevalence state, current efforts need to be continued to reduce the prevalence (Table 6). As it is the first population based survey in the State, trend of prevalence cannot be assessed. The prevalence rate obtained was lower than estimates made out of sentinel surveillance during 2003-2006. HIV Sentinel Surveillance, $2007^{9}$ also indicates the prevalence among ANC attendees has lowered down to $0.6 \%$, which was taken as a proxy indicator of prevalence in general population. This observation is in conformity with NFHS-3 results which also found over-estimation of prevalence of HIV based on sentinel surveillance data.

Based on estimates from 24 rural and 6 urban units, prevalence was found to be higher in urban areas $(1.05 \%)$ as compared to rural areas $(0.67 \%)$, though the difference was not statistically significant $p>0.05$. This finding is consistent with National estimates under NFHS-3 which shows higher HIV prevalence in urban areas $(0.35 \%)$ as compared to rural areas (0.25\%).

District estimates based on population based survey 2007 indicate that in majority of districts, sentinel surveillance over-estimates prevalence of HIV. This study revealed that Dimapur was the only district where HIV prevalence was higher than $1 \%$. Based on Sentinel Surveillance, Tuensang was categorized as one of the districts with very high prevalence of HIV (>3\%). However, Population based study estimated the prevalence to be $0.92 \%$ in this district (Table 7 ).

\begin{tabular}{|c|c|c|c|c|c|c|}
\hline \multirow{2}{*}{ District } & \multirow{2}{*}{ Rural/Urban } & \multicolumn{3}{|c|}{ Sentinel Surveillance } & \multicolumn{2}{|c|}{ PB Survey } \\
\hline & & 2003 & 2004 & 2005 & 2006 & 2007 \\
\hline \multirow{2}{*}{ Dimapur } & U & 1.00 & 0.80 & 1.50 & 2.25 & \multirow{2}{*}{1.17} \\
\hline & $\mathrm{R}$ & 0.79 & 1.20 & 087 & 0.36 & \\
\hline \multirow{2}{*}{ Mokokchung } & U & -- & 2.50 & 0.75 & 1.11 & \multirow{2}{*}{-- } \\
\hline & $\mathrm{R}$ & -- & 0.60 & 1.21 & 0.83 & \\
\hline
\end{tabular}




\begin{tabular}{|lcccccc|} 
Mon & $\mathrm{U}$ & 1.25 & 1.00 & 2.29 & -- & 0.00 \\
& $\mathrm{R}$ & 16.67 & 0.00 & -- & 1.37 & \\
Phek & $\mathrm{U}$ & 2.13 & 0.00 & 1.86 & 0.26 & 0.83 \\
\multirow{2}{*}{ Tuensang } & $\mathrm{R}$ & 7.09 & 0.40 & 0.00 & 0.00 & \\
& $\mathrm{U}$ & 4.25 & 3.60 & 4.73 & 50.0 & 0.92 \\
Wokha & $\mathrm{R}$ & -- & 7.07 & 8.36 & 4.07 & \\
& $\mathrm{U}$ & 0.82 & 0.70 & 1.00 & 0.61 & 0.98 \\
Zunheboto & $\mathrm{R}$ & -- & 0.00 & 2.34 & 0.90 & \\
\multirow{2}{*}{ Kohima } & $\mathrm{U}$ & 0.80 & 1.90 & 1.50 & 2.00 & 0.53 \\
Nagaland State & $\mathrm{R}$ & 0.00 & 0.00 & 0.00 & 0.00 & 0.21 \\
\hline
\end{tabular}

There was lack of consistency in trend of HIV infection based on Sentinel Surveillance in various districts of Nagaland. An attempt was therefore made to observe trends of sero-positivity from data of Integrated Counseling and Testing Centre (ICTC)13 of various districts of Nagaland. Though these data cannot be used as a measure of prevalence, they do indicate the presence of HIV virus in the population. However, the trends suggest that sero-positivity for HIV amongst clients attending ICTCs is consistently reducing in all the districts of Nagaland between 2003-2007 (Figure 4).

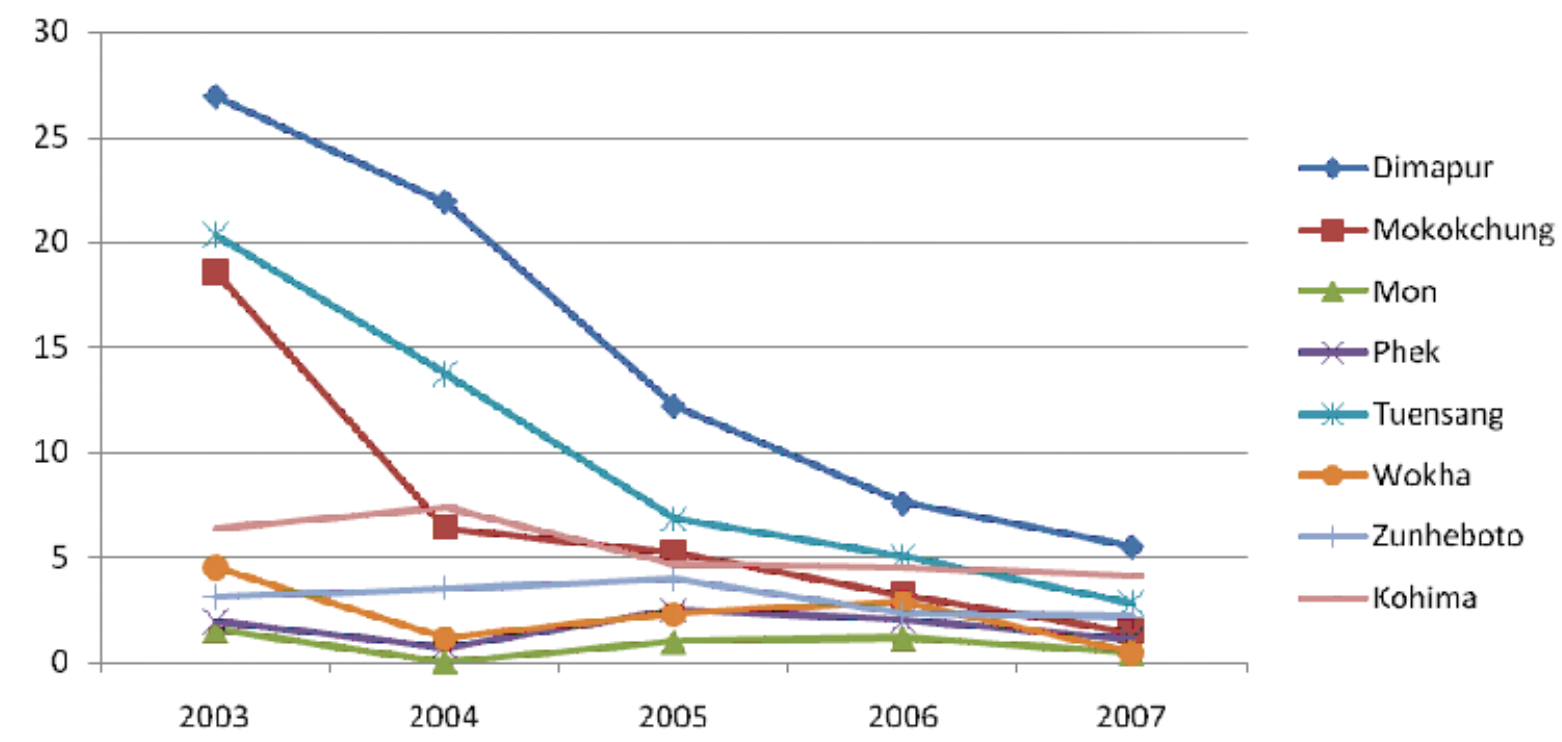

Figure 4: Trend of HIV positive cases in various districts of Nagaland, India, (2003-2007)

Source: CMIS data

Sero-positivity rates amongst ICTC clients across various districts of Nagaland show a declining trend indicating slowing down of HIV transmission. Dimapur, Kohima and Tuensang had higher sero-positivity rates as compared to other districts. Data triangulation needs to be continued further to identify hot spots in the State.

\section{CONCLUSION}

In conclusion, population based survey carried out with a representative sample and good participation rates are very useful to understand the level and distribution of HIV infection. This survey has given an estimate of HIV prevalence in Nagaland to complement information from the National Family 
Heath Survey. Though population based estimates provide better quality of data, it is likely to miss many members of mobile, migrants and other groups at an increased risk of HIV. For evidenced based planning of health programmes such as prevention of mother to child transmission, antiretroviral treatment, and testing and counseling for HIV, future HIV estimates will have to be assessed from various number of data sources to get valid estimates as every methods has its own limitations. Gaps in the knowledge towards HIVIAIDS prevention and available services under National AIDS Control Program were identified and needs to be addressed to ensure higher utilization of services. After interventions are implemented, repeating the survey would help in assessing the impact of interventions on the prevalence of HIVI AIDS.

\section{ACKNOWLEDGMENT}

Authors acknowledge Nagaland State AIDS Control Society and Regional Medical Resource Center (Dibrugarh), National AIDS Research Institute (Pune) and International Institute for Population Sciences (Mumbai) for valuable technical guidance for successful execution of the project. Special thanks to Naga Youth Association for extending full cooperation in getting the survey completed. Survey was funded by the World Health Organization.

\section{REFERENCES}

1. UNAIDS: Report on the Global AIDS Epidemic. Geneva 2006, [http://www.unaids.org/en/HIV_ data/2006GlobalReport/default.asp].

2. UNAIDS/WHO Working Group on Global HIVIAIDS and STI surveillance. Guidelines for measuring national HIV prevalence in population-based surveys. Geneva, UNAIDS/WHO; 2005.

3. Fylkesnes K, Ndhlovu Z, Kasumba K, Mubanga Musonda R, Sichnor M. Studying dynamics of the HIV epidemic:population based data compared with sentinel surveillance in Zambia. AIDS. $1998 \mathrm{Jul}$ 9;12(10):1227-34.
4. Ruiz J, Molitor F, Mc Farland W, A population based door-to-door survey of HIV, STD and risk behaviours among young women in California,USA. Young Women's Survey Group. Int Conf AIDS, 1998;12:433 (abstract no. 23458).

5. Garcia-Calleja JM, Gouws E, Ghys PD. National population based HIV prevalence surveys in subSaharan Africa: results and implications for HIV and AIDS estimates. Sex Transm Infect 2006 June;82 Supplement (3):64-70.

6. Lalit Dandona, Vemu Lakshmi, Talasila Sudha, G.Anil Kumar and Rakhi Dandaona. A population based study of human immunodeficiency virus in south India reveals major differences from sentinel surveillance based estimates. BMC Medcince 2006, 4:31.

7. Angelica Espinosa Miranda, Ninive Camilo Figueiredo, Renylena Schmidt and Kimberly Page Shafer. A population based survey of the prevalence of HIV, Syphilis, Hepatitis B and Hepatitis C Infections, and associated risk factors among young women in Vitoria, Brazil. AIDS and Behaviour Volume 12, Supplement (1) July, 2008.

8. HIV Fact sheets, HIV Sentinel Surveillance Data in India, National AIDS Control Organization, Ministry of Health and Family Welfare, Government of India, 3003-2006.

9. National AIDS Control Organization: HIV Sentinel Surveillance and HIV Estimation in India. A Technical Brief, 2007. New Delhi: Ministry of Health and Family Welfare, Government of India.

10. International Institute for Population Sciences (IIPS) and ORC Macro: National Family Health Survey-3, 2005-06: India Mumbai: IIPS; 2006.

11. Census of India, 2001. Office of the Registrar General of India. [http://www.census2001.org]. Computerized Information Management System (CMIS) of National AIDS Control Organization; December 2008.

12. Behavioral Sentinel Surveillance, National AIDS Control Organization, Ministry of Health and Family Welfare, Government of India, 2006 